\title{
The effect of surgical approach on the outcomes and prognosis of high-risk histologic endometrioid carcinomas
}

\author{
Zhihong Han ${ }^{1}$, Zhong Zheng ${ }^{2}$, Kai Tao ${ }^{1}$, Yanping Yu ${ }^{1}$, Jinping $\mathrm{Wu}^{3}$, Xiaofei Tian ${ }^{1}$ \\ ${ }^{1}$ Department of Gynecologic Oncology, Shaanxi Provincial Tumor Hospital, Xi'an, China; ${ }^{2}$ Department of Gynecologic Oncology, Fudan University \\ Shanghai Cancer Center, Department of Oncology, Shanghai Medical College, Fudan University, Shanghai, China; ${ }^{3}$ Department of Gynecology and \\ Obstetrics, 521 Hospital of Norinco Group Xi'an, Xi'an, China \\ Contributions: (I) Conception and design: Z Han; (II) Administrative support: X Tian, Z Zheng; (III) Provision of study materials or patients: K Tao, \\ Y Yu; (IV) Collection and assembly of data: Z Han, J Wu; (V) Data analysis and interpretation: Z Han, X Tian; (VI) Manuscript writing: All authors; \\ (VII) Final approval of manuscript: All authors. \\ Correspondence to: Jinping Wu. Department of Gynecology and Obstetrics, 521 Hospital of Norinco Group Xi'an, No.12 Zhangba East Road, Yanta \\ District, Xi'an 710000, China. Email: yuq1653@163.com; Xiaofei Tian. Department of Gynecologic Oncology, Shaanxi Provincial Tumor Hospital, \\ 309 Yanta West Road, Yanta District, Xi’an 710061, China. Email: luh6637@163.com.
}

Background High-risk histologic endometrioid carcinomas include poorly differentiated endometrial carcinoma (PDEC), uterine clear cell carcinoma (UCCC), uterine carcinosarcoma (UCS), and uterine papillary serous carcinomas (UPCS). The purpose of this study was to investigate and compare the effect of open surgery and minimally invasive surgery on the prognosis of patients with high-risk endometrial cancer tissue types.

Methods: A retrospective analysis was conducted to investigate 57 UCS or UPCS, 53 UCCC, and 110 PDEC patients receiving initial treatment at the Department of Gynecology in Shaanxi Provincial Tumor hospital and the Affiliated Hospital of Medical College of Xi'an Jiaotong University between February 2010 and January 2015. Prognostic factors were determined using univariate/multivariate analysis, and survival rates were assessed using the Kaplan-Meier method. The Cox regression model was adopted to assess the independent prognostic factors.

Results: Two hundred and twenty patients who met the criteria were included in this study. At the end of follow-up period, 94 patients were still alive. Univariate analysis found that the survival time of the patients was related to staging, adjuvant therapy, and surgical approach. Multivariate analysis revealed that surgical approach, staging, pathology, and adjuvant therapy were independent prognostic factors.

Conclusions: Minimally invasive surgery has a shorter survival time compared to open surgery in women with PDEC, UCCC, UCS, and UPCS. Multivariate analysis confirmed that staging, pathological type, surgical approach, and postoperative adjuvant therapy are independent risk factors for prognosis and affect the survival of women with PDEC, UCCC, UCS, and UPCS.

Keywords: High-risk histologic endometrioid carcinomas; laparoscopic surgery; laparotomy; overall survival

Submitted Nov 06, 2020. Accepted for publication Jan 02, 2021.

doi: $10.21037 /$ gs-20-887

View this article at: http://dx.doi.org/10.21037/gs-20-887

\section{Introduction}

The incidence of endometrial cancer has been increasing in recent years, with a 5 -year survival rate of approximately $81 \%$ in the United States (1). In China, the 5 -year survival rate for endometrial cancer can also exceed $80 \%$. High-risk histologic endometrioid carcinomas account for $15-20 \%$ of cases, and include poorly differentiated endometrioid carcinomas (PDEC) (2), uterine papillary serous carcinomas (UPCS), uterine clear cell carcinoma (UCCC), and uterine carcinosarcoma (UCS) (3). These high-risk histologic 
tumors account for more than $50 \%$ of endometrioid carcinoma deaths $(2,4-6)$. They have high malignancy rates and poor prognoses, and are liable to distant metastasis, yet are difficult to detect early $(7,8)$. Unsurprisingly, improvement of the survival rate of the patients has become a controversial topic. Although most studies have reported no differences between open and minimally invasive surgery for endometrial cancer in terms of their complications and long-term survival (9), only few studies have reported on the impact of surgical approach selection on the longterm survival of high-risk endometrial cancer patients. The present study primarily addresses the relationship between surgical approach selection and long-term survival in high-risk endometrial carcinomas with the expectation of providing certain strategies for clinical treatment. In addition, the univariate analysis in this article found that the patient's survival time is related to staging, adjuvant treatment and surgical methods. Multivariate analysis showed that surgical methods, staging, pathology and adjuvant therapy were independent prognostic factors. These are novel and original, and have great guiding significance for future clinical work. We present the following article in accordance with the STROBE reporting checklist (available at http://dx.doi.org/10.21037/gs-20-887).

\section{Methods}

Fifty-seven patients with UCS or UPCS, 53 with UCCC, and 110 with PDEC who underwent primary surgery at the Affiliated Shaanxi Provincial Tumor Hospital of the Medical College of Xi'an Jiaotong University between February 2010 and December 2015 were retrospectively reviewed. All procedures performed in this study involving human participants were in accordance with the Declaration of Helsinki (as revised in 2013). The study protocol was approved by the institutional review board at Xi'an Jiaotong University. Individual consent for this retrospective analysis was waived.

All patients underwent surgery to determine the pathological stage, including debulking surgery. The patients underwent hysterectomy and bilateral adnexectomy, and no neoadjuvant chemotherapy was administered (except for stage IV patients). Patients were excluded based on the following criteria: (I) those who had received preoperative radiation therapy without the presence of other cancers, except for patients undergoing laparoscopic surgery or laparotomy; (II) those with highly differentiated endometrioid adenocarcinoma but death due to other diseases; and (III) those with incomplete removal of the uterus. All patients were followed up after treatment. Surgical pathological staging was based on FIGO 2009. The patients were divided into two groups, with one group undergoing open abdominal surgery and the other receiving minimally invasive surgery, including laparoscopic surgery and vaginal combined laparoscopic surgery. Follow-up was performed every 3 months for the first 2 years, every 6 months at the beginning of the third year, and every year after 5 years. For other cancers, all diagnoses were made by our gynecologic pathologists.

\section{Statistical analysis}

Statistical analyses were performed using SPSS Statistics version 20.0 (IBM Co., Armonk, NY, USA). The chi-square test was applied to compare the ratios between the groups. The survival graph was analyzed via the Kaplan-Meier method. Kaplan-Meier survival curves were generated, and the survival differences were quantified using the log-rank test (univariate analysis). Multivariate analysis was employed to analyze the independent prognostic factors using the Cox regression model. Forest plots were used for subgroup analyses to compare the prognostic differences between these malignant endometrial carcinomas (EC). A P value of $<0.05$ was considered statistically significant.

\section{Results}

\section{Data source}

Of the 220 patients included this study, two patients died of non-neoplastic diseases during the follow-up period, and 94 patients were still alive at the end of the follow-up period. The overall 5 -year survival rate was $72 \%$ and the median survival was 67.52 months.

In total, 220 patients were diagnosed with PDEC, UCCC, UCS, and UPCS and satisfied the inclusion criteria. The median age at diagnosis was 58.0 years (range, $42-78$ years). All patients in the study underwent surgery. The average body mass index (BMI) of all patients was $24.1 \pm 3.1 \mathrm{~kg} / \mathrm{m}^{2}$, and 100 patients $(45.5 \%)$ had a BMI of 25 or more. See Table 1.

\section{Clinical treatment}

The effect of clinical characteristics on survival time was analyzed using a single factor. The median survival time was 
Table 1 The demographic, surgical, and histopathological features of all patients in the study cohort

\begin{tabular}{|c|c|c|}
\hline Variable & Cases & Percentage \\
\hline \multicolumn{3}{|l|}{ Age (year) } \\
\hline$\geq 60$ & 140 & 63.6 \\
\hline$<60$ & 80 & 36.4 \\
\hline \multicolumn{3}{|l|}{ Body mass index $\left(\mathrm{kg} / \mathrm{m}^{2}\right)$} \\
\hline$<25$ & 120 & 54.5 \\
\hline$\geq 25$ & 100 & 45.5 \\
\hline \multicolumn{3}{|l|}{ Surgical mode } \\
\hline Open surgery & 106 & 48.2 \\
\hline Laparoscopic surgery & 114 & 51.8 \\
\hline \multicolumn{3}{|l|}{ Postoperative adjuvant therapy } \\
\hline Yes & 151 & 68.6 \\
\hline No & 69 & 31.4 \\
\hline \multicolumn{3}{|l|}{ Pathological type } \\
\hline $\begin{array}{l}\text { Poorly differentiated endometrioid } \\
\text { adenocarcinoma }\end{array}$ & 110 & 50.0 \\
\hline Clear cell carcinoma & 53 & 24.1 \\
\hline $\begin{array}{l}\text { Carcinosarcoma or plasma breast } \\
\text { cancer }\end{array}$ & 57 & 25.9 \\
\hline \multicolumn{3}{|l|}{ FIGO stage } \\
\hline I stage & 87 & 39.5 \\
\hline II stage & 74 & 33.6 \\
\hline III stage & 50 & 22.7 \\
\hline IV stage & 9 & 4.2 \\
\hline \multicolumn{3}{|l|}{ Cancer antigen (CA125) value } \\
\hline$\leq 35$ & 100 & 45.5 \\
\hline$>35$ & 120 & 54.5 \\
\hline \multicolumn{3}{|l|}{ Lymph node metastasis } \\
\hline Yes & 44 & 20.0 \\
\hline No & 176 & 80.0 \\
\hline \multicolumn{3}{|l|}{ Depth of tumor invasion } \\
\hline$\leq 1 / 2$ & 58 & 26.4 \\
\hline$>1 / 2$ & 162 & 73.6 \\
\hline
\end{tabular}

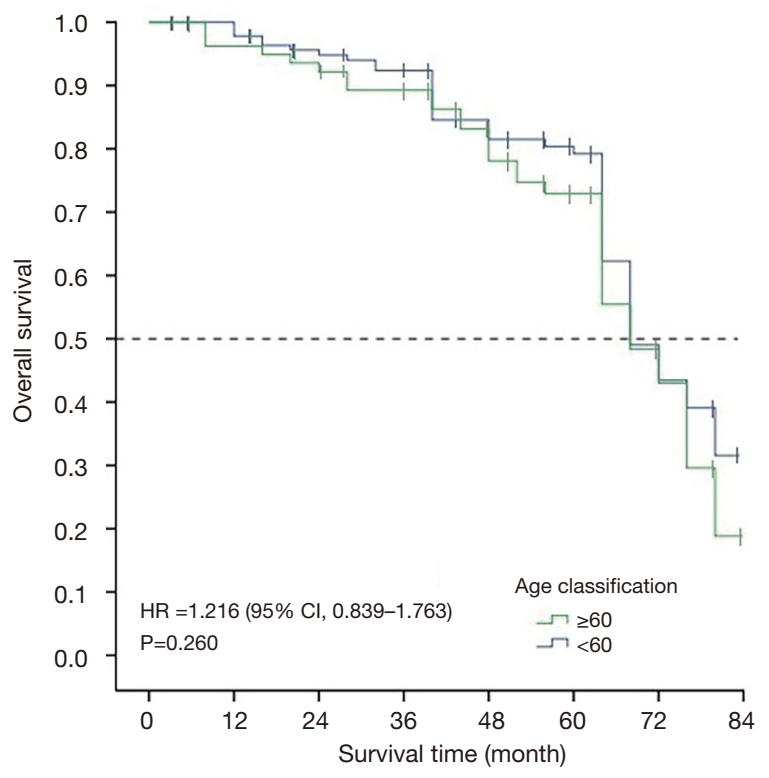

Figure 1 Overall survival between patients aged over 60 years and patients aged under 60 years.

67.08 months for patients under the age of 60 years, and 67.71 months for those over 60 years, and the difference was not statistically significant $(\mathrm{P}=0.260)$. The 5 -year survival rate was $69 \%$ and $74 \%$ for those under the age of 60 years and those over 60 years, respectively (Figure 1).

The 5-year survival rate and median survival time of patients with a BMI of less than 25 were $78 \%$ and 67.78 months, respectively. For patients with a BMI greater than or equal to 25 , the 5 -year survival rate and median survival time were $66 \%$ and 67.32 months, respectively. There were no significant statistical differences in the survival time of patients with patients with different BMIs (Figure 2).

The 5 -year survival rate and median survival time of laparotomy patients were $80 \%$ and 73.34 months, respectively, and $58 \%$ and 62.62 months, respectively, for laparoscopy patients. The difference in survival time was statistically significant in the different surgical modes $\left(\chi^{2}=8.968, \mathrm{P}=0.003\right)$ (Figure 3).

The 5-year survival rate and median survival time of 58 patients with poorly differentiated adenocarcinoma 


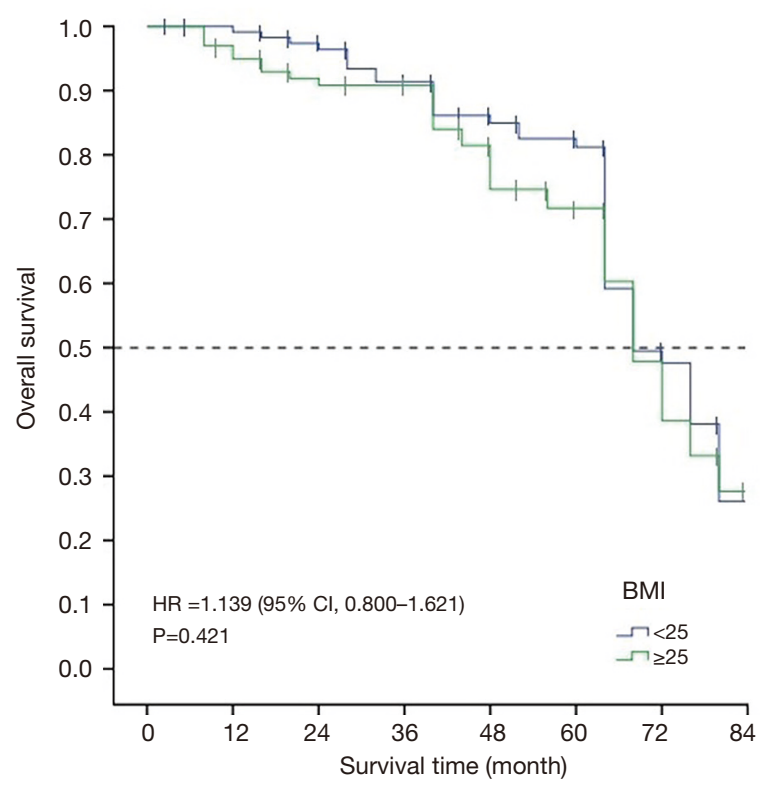

Figure 2 Overall survival between patients with a BMI less than 25 and patients with a BMI greater than or equal to 25. BMI, body mass index.

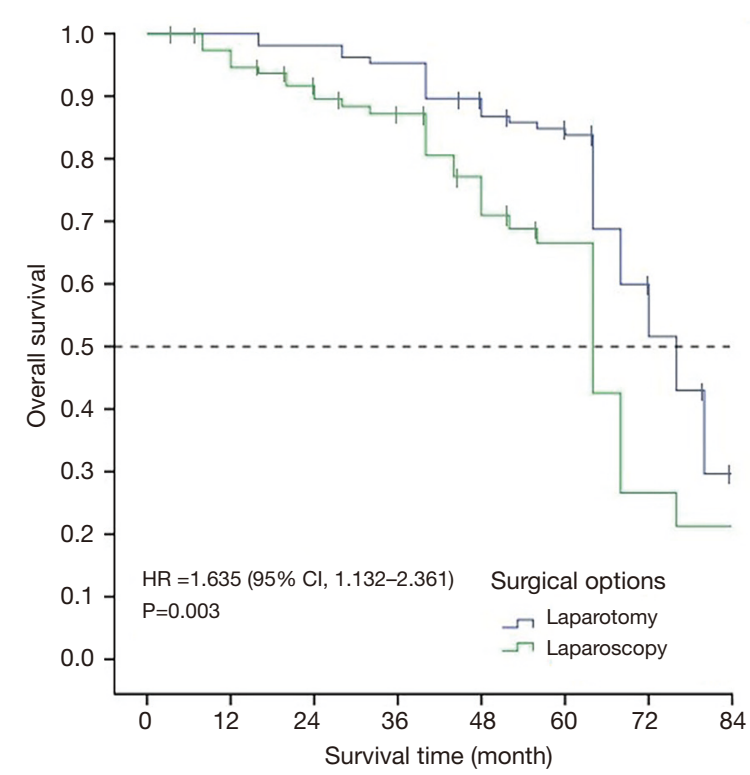

Figure 3 Overall survival between laparotomy and laparoscopy patients.

undergoing laparotomy were $85 \%$ and 75.56 months, respectively, and for patients with poorly differentiated adenocarcinoma undergoing laparoscopic surgery were $75 \%$ and 67.61 months, respectively. There was no statistical

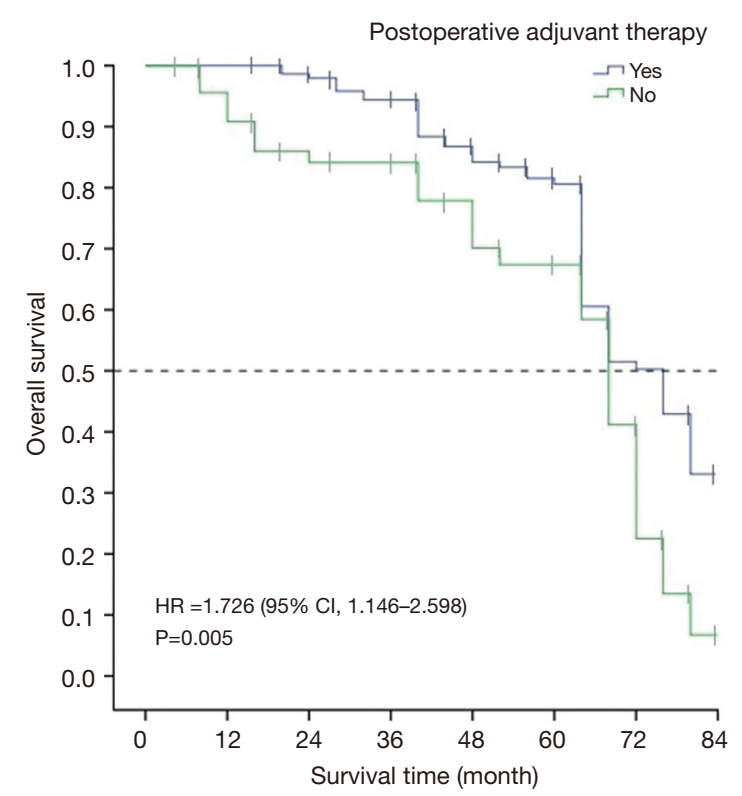

Figure 4 Overall survival between patients receiving postoperative adjuvant therapy and those not receiving postoperative adjuvant therapy.

difference between the two groups $\left(\chi^{2}=0.702, \mathrm{P}=0.402\right)$.

The 5 -year survival rate and median survival time in 24 patients with clear cell carcinoma who underwent laparotomy were $72 \%$ and 62.63 months, respectively. The 5 -year survival rate and median survival time of the patients performing laparoscopy were $54 \%$ and 61.30 months, respectively, and the difference between the two groups was statistically significant $\left(\chi^{2}=4.236, \mathrm{P}=0.040\right)$.

The 5 -year survival rate and median survival time of 22 patients with UCS or UPCS were $65 \%$ and 66.93 months, respectively, and of patients with UCS or UPCS were $42 \%$ and 60.75 months, and the difference between the two groups was statistically significant $\left(\chi^{2}=7.075, \mathrm{P}=0.008\right)$.

The 5 -year survival rate and median survival time of patients receiving adjuvant therapy were $77 \%$ and 72.15 months, respectively, and for patients receiving no adjuvant therapy were $60 \%$ and 65.96 months, respectively. The differences in the survival time between patients receiving adjuvant therapy and those that did not receive adjuvant therapy was statistically significant $\left(\chi^{2}=7.958\right.$, $\mathrm{P}=0.005$ ) (Figure 4).

The 5-year survival rate and the median survival time of patients with PDEC were $82 \%$ and 75.21 months, respectively, $66 \%$ and 61.91 months, respectively, for patients with clear cell carcinoma, and $54 \%$ and 62.64 


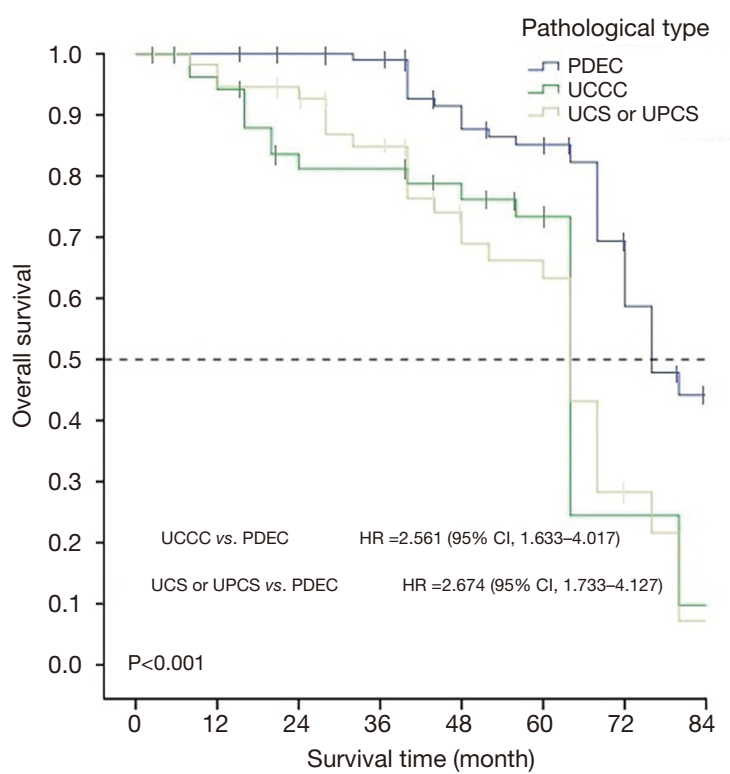

Figure 5 Overall survival among patients with poorly differentiated adenocarcinoma, patients with clear cell carcinoma, and patients with carcinosarcoma or plasma. PDEC, poorly differentiated endometrial carcinoma; UCCC, uterine clear cell carcinoma; UCS, uterine carcinosarcoma; UPCS, uterine papillary serous carcinomas.

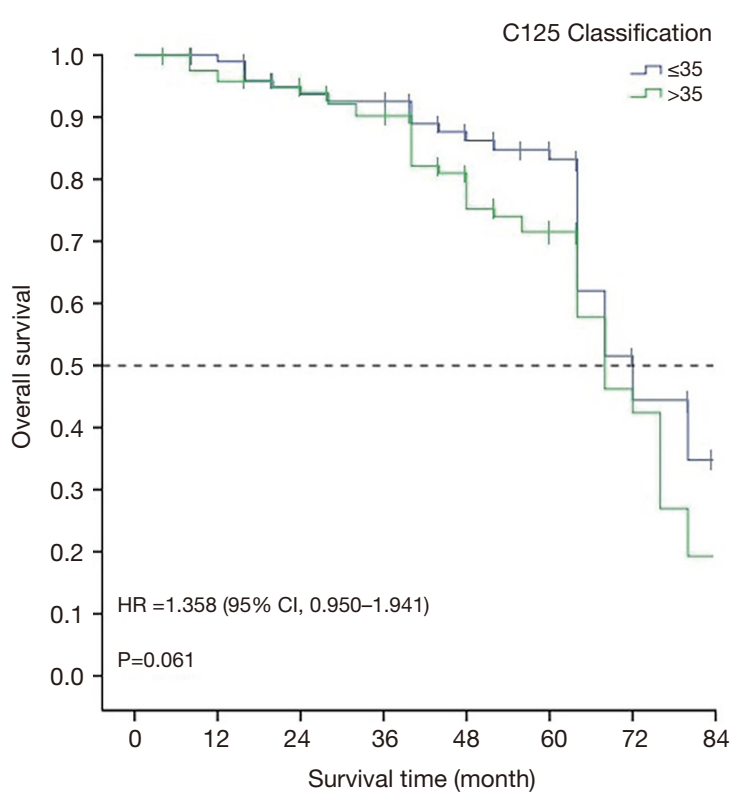

Figure 6 Overall survival of patients with normal CA125 and those with abnormal CA125 values. months, respectively for patients with UCS or UPCS. Survival time was the different significant on the pathological types $\left(\chi^{2}=32.627, \mathrm{P}<0.001\right)$ (Figure 5$)$.

The 5 -year survival rate and median survival time of stage I patients were $87 \%$ and 75.27 months, respectively, $76 \%$ and 66.97 months, respectively, for stage II patients, and $34 \%$ and 60.53 months, respectively, for stage III or IV patients. The differences between patients at different pathological stages were statistically significant $\left(\chi^{2}=20.727\right.$, $\mathrm{P}<0.001)$.

The 5-year survival rate and median survival time of patients with normal CA125 were $79 \%$ and 86 months, respectively, and $66 \%$ and 66.69 months, respectively, for patients with abnormal CA125. There was no statistical difference in the survival time of patients with normal CA125 and those with abnormal CA125 values $\left(\chi^{2}=3.501\right.$, $\mathrm{P}=0.061$ ) (Figure 6).

The 5 -year survival rate and median survival time of patients with lymph node metastasis were $48 \%$ and 65.67 months, respectively, and 76\% and 68.06 months, respectively, for patients without lymph node metastasis. There was no statistical difference in the survival time of patients with and without lymph node metastasis $\left(\chi^{2}=2.948\right.$, $\mathrm{P}=0.086$ ) (Figure 7).

The 5 -year survival rate and median survival time of patients with a tumor invasion depth of less than $1 / 2$ were $74 \%$ and 68.82 , respectively, and $71 \%$ and 66.67 months, respectively, for patients with a tumor invasion depth of greater than $1 / 2$. The differences between these groups of patients were not statistically significant $\left(\chi^{2}=0.945, \mathrm{P}=0.331\right)$ (Figure 8).

Variables that exhibited statistical significance in the univariate analysis were incorporated into the Cox regression equation for analysis. It was concluded that postoperative adjuvant therapy, pathological stage, pathological type, and surgical mode were all independent risk factors affecting the survival time of patients. See Table 2.

\section{Discussion}

High-risk histologic endometrial cancer is a subtype of endometrial carcinoma and has a worse prognosis. The incidence of endometrial cancer increases annually, with a greater number of patients being diagnosed with highrisk histologic endometrial cancers. However, there has not 


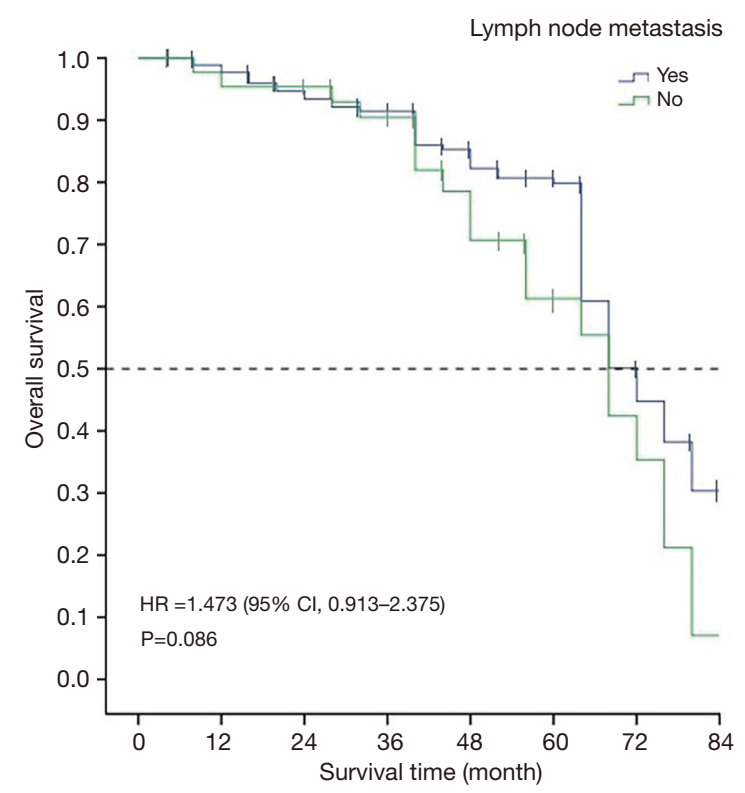

Figure 7 Overall survival between patients with lymph node metastasis and those without lymph node metastasis.



Figure 8 Overall survival between patients with a tumor invasion depth of less than $1 / 2$ and patients with a tumor invasion depth of greater than $1 / 2$.

been any major improvement to the 5 -year survival rate and overall survival of patients, which is primarily attributable to the fact that patients with high-risk histology endometrial cancer being less and there is less related research available $(10,11)$. In recent years, laparoscopic surgery has become a popular surgical method for endometrial cancer, and there is a trend towards replacing traditional open surgery. However, not all patients with endometrial cancer are suitable for laparoscopic surgery. Although our study is retrospective, it can help avoid subjective differences, such as the biases that exist with the way that doctors choose to operate.

We observed more advanced endometrial carcinosarcoma patients, but fewer of them were obese. There are also more advanced patients with UCS (12), UCCC, and UPSC. In this study, we showed that staging is an independent prognostic factor for high-risk endometrial carcinoma tissue types. This is attributable to two main factors. Firstly, preoperative and postoperative stages are inconsistent due to preoperative limitation in the uterus, postoperative limitations beyond the uterus, and distant metastasis, particularly in UCS (12), UCCC, and UPSC (10). Secondly, the symptoms and clinical manifestations are not specific (6), and imaging studies did not detect micrometastases. Therefore, there are more patients with these three types of advanced endometrial cancer, with significantly reduced survival rates and poor prognoses (12).

It is well known that the initial treatment of tumor patients is critical. Although minimally invasive surgery for endometrial cancer offers shorter operation times, less blood loss, and shorter hospitalization times than open surgery, open surgery does not affect the later adjuvant treatment of patients. There was no significant difference in mean length of hospital stay (13). In this study, we focused on overall survival time and survival improvement. The operation methods and approaches were different, which meant that patients had different outcomes. Our study found that the survival rate of open surgery was higher than that of minimally invasive surgery among women with UCS, UCCC, and UPSC. In these patients, median and overall survival times were prolonged.

Surgical approach was also an independent risk factor in the multivariate analysis. UPS and UCCC spread to the abdominal peritoneum more frequently than PDEC, which was also confirmed by Greggi et al. (10). This may be related to the use of hysteroscopy at preoperative diagnosis, which may lead to metastasis through the fallopian tube and into the abdominal cavity. However, the specific reasons need to be further explored, and stratified analysis and additional research may be required. Clearly, the choice of surgical approach for high-risk endometrial cancer 
Table 2 Cox regression equation for analysis

\begin{tabular}{|c|c|c|c|c|c|c|}
\hline Variable & Coefficient & Standard error & Statistic & $P$ value & OR value & $95 \% \mathrm{Cl}$ \\
\hline Surgical mode & 0.557 & 0.195 & 8.145 & 0.004 & 1.746 & $1.191-2.559$ \\
\hline Postoperative adjuvant therapy & 0.673 & 0.210 & 10.285 & 0.001 & 1.961 & $1.299-2.959$ \\
\hline Pathological stage & 0.576 & 0.125 & 21.406 & $<0.001$ & 1.780 & $1.394-2.272$ \\
\hline
\end{tabular}

tissue types is controversial. Personally, I think it is good to use fluorescence guidance during surgery for high-risk endometrial cancer.

In poorly differentiated endometrial carcinoma (PDEC) patients, we found that there was no difference in the progression-free and overall survival between open and laparoscopic surgeries, which is consistent with the findings of some gynecologists (14). However, in UCS, UCCC, and UPSC patients, we observed a difference between laparoscopic surgery and open surgery. We also found that overall survival and disease-free survival was higher in open surgery compared to minimally invasive surgery, which is inconsistent with the results of previous studies. At present, only patients with early-stage endometrial cancer can be followed up due to the limitation of surgical mode. Previous studies have shown that minimally invasive surgery is likely to be regarded as the standard surgical method for endometrial carcinoma (9,15-17). Previous research have also reported the different surgical approaches in EC $(13,18,19)$. Koskas et al. (20) reported that there was no notable difference in overall survival between minimally invasive surgery and open surgery, however this study included a higher proportion of early-stage patients. A previous study showed that women with type II endometrial cancer that underwent minimally invasive hysterectomies experienced fewer complications and similar survival outcomes compared with those who underwent open surgery. There was also no difference in the overall survival between FIGO stage I and stage II cancer patients (21). Some authors have reported no significant difference in disease-free survival and overall survival at 21 months (median) follow-up time between laparotomy and laparoscopic or robotic surgery (22), however these results need to be confirmed.

The current study provides surgical methods for UCS, UCCC, and UPSC, which have been insufficiently investigated. We recommend that UCS, UCCC, and UPSC patients be mindful when choosing a surgical approach; we suggest opting for open surgery, despite shorter hospital stays, faster recovery, and fewer complications with minimally invasive surgery. This is because both the 5 -year and overall survival time for open surgery is better than that of minimally invasive surgery. Furthermore, UPSC and UCCC, which may coexist with UPSC, have a propensity to spread beyond the uterus and a clinical behavior similar to ovarian cancer with relapse and metastases in the upper abdomen, retina, and peritoneum $(10,23,24)$. Also, micrometastases are sometimes missed in minimally invasive surgery, resulting in extensive metastasis caused by residual lesions. Moreover, the operation cannot reach complete staging, and radiographic examination cannot fully assess preoperative staging. Secondly, intraoperative uterine tumor overflow may result in tumor implantation, or the uterus was not removed integrally from the vagina, thus considering long-term survival, we cannot select minimally invasive surgery for all patients with UCS, UCCC, and UPSC. Monterossi et al. (21) reported that the overall survival of patients with advanced FIGO stage III type II endometrial cancer treated with open surgery is better than those treated with minimally invasive surgery, although the differences were not statistically significant $(\mathrm{P}=0.063)$. Maybe, this is because the patient's disease is more severe and has a tendency to spread outside the uterus. The clinical manifestations are similar to ovarian cancer, which can recur and metastasize in the upper abdomen, retina and peritoneum. In addition, minimally invasive surgery sometimes misses micrometastasis, resulting in residual lesions causing widespread metastasis. Surgery cannot reach the complete staging, and imaging examination cannot fully evaluate the preoperative staging. Secondly, intraoperative uterine tumor overflow may lead to tumor implantation, or the uterus is not completely separated from the vagina, which affects long-term survival.

Finally, it is worth noting that our study found that postoperative adjuvant therapy was associated with better overall survival and the difference was also statistically 
significant, which is consistent with most previous studies $(25,26)$.

In conclusion, our study confirmed that high-risk endometrial cancer tissue types are associated with a poor prognosis. Also, UCS, UCCC, and UPSC are more likely to metastasize than PDEC. Although our study confirmed that open surgery has a higher survival rate than minimally invasive surgery in UCS, UCCC, and UPSC, this finding remains controversial due to the small sample size. Multicenter prospective studies are needed to further validate these results. At present, we recommend open surgery for high-risk endometrial cancer tissue types, especially considering that not all patients with endometrial cancer are suitable for minimally invasive surgery.

\section{Acknowledgments}

Funding: None.

\section{Footnote}

Reporting Checklist: The authors have completed the STROBE reporting checklist. Available at http://dx.doi. org/10.21037/gs-20-887

Data Sharing Statement: Available at http://dx.doi. org/10.21037/gs-20-887

Conflicts of Interest: All authors have completed the ICMJE uniform disclosure form (available at http://dx.doi. org/10.21037/gs-20-887). The authors have no conflicts of interest to declare.

Ethical Statement: The authors are accountable for all aspects of the work in ensuring that questions related to the accuracy or integrity of any part of the work are appropriately investigated and resolved. All procedures performed in this study involving human participants were in accordance with the Declaration of Helsinki (as revised in 2013). The study protocol was approved by the institutional review board at Xi'an Jiaotong University. Individual consent for this retrospective analysis was waived.

Open Access Statement: This is an Open Access article distributed in accordance with the Creative Commons Attribution-NonCommercial-NoDerivs 4.0 International License (CC BY-NC-ND 4.0), which permits the noncommercial replication and distribution of the article with the strict proviso that no changes or edits are made and the original work is properly cited (including links to both the formal publication through the relevant DOI and the license). See: https://creativecommons.org/licenses/by-nc-nd/4.0/.

\section{References}

1. Siegel RL, Miller KD, Jemal A. Cancer statistics, 2019. CA Cancer J Clin 2019;69:7-34.

2. Voss MA, Ganesan R, Ludeman L, et al. Should grade 3 endometrioid endometrial carcinoma be considered a type 2 cancer-a clinical and pathological evaluation. Gynecol Oncol 2012;124:15-20.

3. Zhang $\mathrm{C}, \mathrm{Hu} \mathrm{W}$, Jia $\mathrm{N}$, et al. Uterine carcinosarcoma and high-risk endometrial carcinomas: a clinicopathological comparison. Int J Gynecol Cancer 2015;25:629-36.

4. Vogel TJ, Knickerbocker A, Shah CA, et al. An analysis of current treatment practice in uterine papillary serous and clear cell carcinoma at two high volume cancer centers. J Gynecol Oncol 2015;26:25-31.

5. Versluis MA, de Jong RA, Plat A, et al. Prediction model for regional or distant recurrence in endometrial cancer based on classical pathological and immunological parameters. Br J Cancer 2015;113:786-93.

6. Ji Q, Wang X, Jiang J, et al. Sentinel lymph node mapping in high-risk endometrial cancer: a systematic review and meta-analysis. Gland Surg 2020;9:2091-105.

7. de Boer SM, Powell ME, Mileshkin L, et al. Adjuvant chemoradiotherapy versus radiotherapy alone for women with high-risk endometrial cancer (PORTEC-3): final results of an international, open-label, multicentre, randomised, phase 3 trial. Lancet Oncol 2018;19:295-309.

8. Kim HJ, Kim TJ, Lee YY, et al. A comparison of uterine papillary serous, clear cell carcinomas, and grade 3 endometrioid corpus cancers using 2009 FIGO staging system. J Gynecol Oncol 2013;24:120-7.

9. Bregar AJ, Melamed A, Diver E, et al. Minimally Invasive Staging Surgery in Women with Early-Stage Endometrial Cancer: Analysis of the National Cancer Data Base. Ann Surg Oncol 2017;24:1677-87.

10. Greggi S, Mangili G, Scaffa C, et al. Uterine papillary serous, clear cell, and poorly differentiated endometrioid carcinomas: a comparative study. Int J Gynecol Cancer 2011;21:661-7.

11. Pandita P, Wang X, Jones DE, et al. Unique Molecular Features in High-Risk Histology Endometrial Cancers. Cancers (Basel) 2019;11:1665.

12. Zhu J, Wen H, Bi R, et al. Clinicopathological 
characteristics, treatment and outcomes in uterine carcinosarcoma and grade 3 endometrial cancer patients: a comparative study. J Gynecol Oncol 2016;27:e18.

13. Ghazali WA, Jamil SA, Sharin IA. Laparoscopic versus Laparotomy: Staging Surgery for Endometrial Cancer - Malaysia's Early Experience. Gynecol Minim Invasive Ther 2019;8:25-9.

14. Fader AN, Seamon LG, Escobar PF, et al. Minimally invasive surgery versus laparotomy in women with high grade endometria. Gynecol Oncol 2012;126:180-5.

15. Dieterich M, Schroter V, Stubert J, et al. Oncologic Outcome of Patients with (Low-Risk) Endometrial Carcinoma Undergoing Laparotomy versus Minimally Invasive Hysterectomy: A Retrospective Analysis. Oncol Res Treat 2019;42:636-49.

16. Wright JD, Burke WM, Tergas AI, et al. Comparative Effectiveness of Minimally Invasive Hysterectomy for Endometrial Cancer. J Clin Oncol 2016;34:1087-96.

17. Janda M, Gebski V, Davies LC, et al. Effect of Total Laparoscopic Hysterectomy vs Total Abdominal Hysterectomy on Disease-Free Survival Among Women With Stage I Endometrial Cancer: A Randomized Clinical Trial. JAMA 2017;317:1224-33.

18. Bourgin C, Lambaudie E, Houvenaeghel G, et al. Impact of age on surgical staging and approaches (laparotomy, laparoscopy and robotic surgery) in endometrial cancer management. Eur J Surg Oncol 2017;43:703-9.

19. Jørgensen SL, Mogensen O, Wu C, et al. Nationwide Introduction of Minimally Invasive Robotic Surgery for Early-Stage Endometrial Cancer and Its Association With

Cite this article as: Han Z, Zheng Z, Tao K, Yu Y, Wu J, Tian $X$. The effect of surgical approach on the outcomes and prognosis of high-risk histologic endometrioid carcinomas. Gland Surg 2021;10(1):355-363. doi: 10.21037/gs-20-887
Severe Complications. JAMA Surg 2019;154:530-8.

20. Koskas M, Jozwiak M, Fournier M, et al. Long-term oncological safety of minimally invasive surgery in highrisk endometrial cancer. Eur J Cancer 2016;65:185-91.

21. Monterossi G, Ghezzi F, Vizza E, et al. Minimally Invasive Approach in Type II Endometrial Cancer: Is It Wise and Safe? J Minim Invasive Gynecol 2017;24:438-45.

22. Manchana T, Puangsricharoen P, Sirisabya N, et al. Comparison of Perioperative and Oncologic Outcomes with Laparotomy, and Laparoscopic or Robotic Surgery for Women with Endometrial Cancer. Asian Pac J Cancer Prev 2015;16:5483-8.

23. Stewart CJ, Doherty DA, Havlat M, et al. Transtubal spread of endometrial carcinoma: correlation of intraluminal tumour cells with tumour grade, peritoneal fluid cytology, and extra-uterine metastasis. Pathology 2013;45:382-7.

24. Fader AN, Boruta D, Olawaiye AB, Gehrig PA. Uterine papillary serous carcinoma: epidemiology, pathogenesis and management. Curr Opin Obstet Gynecol 2010;22:21-9.

25. Tanner EJ, Leitao MM, Jr., Garg K, et al. The role of cytoreductive surgery for newly diagnosed advanced-stage uterine carcinosarcoma. Gynecol Oncol 2011;123:548-52.

26. Koh WJ, Abu-Rustum NR, Bean S, et al. Uterine Neoplasms, Version 1.2018, NCCN Clinical Practice Guidelines in Oncology. J Natl Compr Canc Netw 2018;16:170-99.

(English Language Editor: A. Kassem) 